\title{
Treatment of Acute Kidney Injury Complicating Septic Shock with EMiC2 High-cutoff Hemofilter: Case Series
}

\author{
Hoi-Ping Shum, King-Chung Chan', Wing-Wa Yan, Tak Mao Chan ${ }^{2}$ \\ Department of Intensive Care, Pamela Youde Nethersole Eastern Hospital, 'Department of Anesthesia and Intensive Care, Tuen Mun Hospital, \\ 2Department of Medicine, The University of Hong Kong, Queen Mary Hospital, Hong Kong SAR, China
}

\section{Abstract}

Introduction: Extracorporeal blood purification therapies have been proposed to improve outcomes of patients with severe sepsis, with or without accompanying acute kidney injury (AKI), by removal of excessive inflammatory mediators. Materials and Methods: We report our experience with EMiC2 high-cutoff continuous venovenous hemofiltration/hemodialysis (HCO-CVVH/HD) in seven patients with AKI complicating septic shock. Results: The median treatment duration was $71 \mathrm{~h}$, and the procedure was well tolerated. Trough serum albumin level of $20 \mathrm{~g} / \mathrm{L}$ was observed after $2 \mathrm{~h}$ of treatment and none of the patients required albumin supplement. The hospital mortality rate was $29 \%$, which appeared more favorable than the predicted mortality of $60 \%-78 \%$ based on disease severity scores. Circulating levels of interleukin-6 (IL-6), IL-10, and tumor necrosis factor-alpha improved over time. Conclusion: This case series shows that HCO-CVVH/CVVHD using EMiC2 hemofilter may provide good cytokine modulation, when used along with good quality standard sepsis therapy. A further large-scale prospective randomized controlled trial is recommended.

Keywords: Acute kidney injury, high-cutoff hemofilter, septic shock

\section{INTRODUCTION}

During sepsis, triacylated peptides, diacylated peptides, or lipopolysaccharides (LPS) are released by pathogenic microorganisms and are recognized by the toll-like receptors (TLRs) located on the surface of antigen-presenting cells. ${ }^{[1,2]}$ TLRs also recognize locally produced damage-associated molecular patterns (DAMPs) from ischemic renal tissue and circulating DAMPs released from extensive extrarenal tissue damage in sepsis. ${ }^{[3]}$ This triggers the activation of leukocytes, endothelial cells, and epithelial cells that release more inflammatory mediators such as tumor necrosis factor- $\alpha$ (TNF- $\alpha$ ), interleukin-1 (IL-1), IL-6, IL-8, and IL-10, causing cellular and tissue damage. ${ }^{[4,5]}$ This situation of "cytokine storm" provides the basis for the concept of immunomodulation in the management of patients with severe sepsis. Treatment with low-dose corticosteroids accelerates septic shock reversal but is not associated with survival benefits. ${ }^{[6,7]}$ The clinical benefit of intravenous immunoglobulin and anti-TNF- $\alpha$ in the treatment of severe sepsis remains controversial and inconclusive. ${ }^{[8,9]}$

\begin{tabular}{|l|l|}
\hline \multicolumn{2}{|c|}{ Access this article online } \\
\hline Quick Response Code: & Website: \\
\hline & www.ijccm.org \\
\hline & \\
\hline
\end{tabular}

Extracorporeal blood purification therapies have been proposed to improve outcomes of patients with severe sepsis with or without acute kidney injury (AKI) by the removal of excessive inflammatory mediators from the blood compartment. ${ }^{[10,11]}$ Some inflammatory mediators have relatively large molecular size, i.e., $17 \mathrm{kDa}$ for TNF- $\alpha, 26 \mathrm{kDa}$ for IL-6, and $8 \mathrm{kDa}$ for IL-8. Conventional high-flux hemofilter has a cutoff of approximately $20 \mathrm{kDa}$, which may not be able to achieve effective clearance for all relevant sepsis-related cytokines. ${ }^{[12,13]}$ High-cutoff (HCO) membranes have clinical cutoff points of $40-100 \mathrm{kDa} \cdot{ }^{[14]}$ In this regard, HCO hemofiltration has been reported to confer good cytokine clearance in patients with septic shock. ${ }^{[15-17]}$ A literature review by Villa, which included five clinical studies, concluded that the removal of the inflammatory mediators by $\mathrm{HCO}$ technique was associated

Address for correspondence: Dr. Hoi-Ping Shum 3 Lok Man Road, Chai Wan, Hong Kong SAR, China. E-mail: shumhp@ha.org.hk

This is an open access article distributed under the terms of the Creative Commons Attribution-NonCommercial-ShareAlike 3.0 License, which allows others to remix, tweak, and build upon the work non-commercially, as long as the author is credited and the new creations are licensed under the identical terms.

For reprints contact: reprints@medknow.com

How to cite this article: Shum HP, Chan KC, Yan WW, Chan TM. Treatment of acute kidney injury complicating septic shock with EMiC2 high-cutoff hemofilter: Case series. Indian J Crit Care Med 2017;21:751-7. 
with a significant improvement in hemodynamic condition, oxygenation indices, and organ dysfunction. ${ }^{[18]}$

We hereby report our experience with EMiC2 (Fresenius SE, Bad Homburg, Germany) HCO continuous venovenous hemofiltration (HCO-CVVH) or hemodialysis (HCO-CVVHD) in patients with severe septic shock complicated by AKI.

\section{Materials and Methods}

This study was a prospective case series from a 23-bed adult medical-surgical Intensive Care Unit (ICU) in a regional medical center in Hong Kong. The study was approved by the institutional ethics committee. We enrolled patients who fulfilled the following inclusion criteria: (1) age $\geq 18$; (2) presence of septic shock as defined by the American College of Chest Physicians/Society of Critical Care Medicine/European Society of Intensive Care Medicine criteria; and ${ }^{[19-21]}$ (3) presence of AKI as defined by the Kidney Disease Improving Global Outcomes (KDIGO). ${ }^{[22]}$ pregnant patients, patients with documented chronic kidney disease Stage 5 (glomerular filtration rate $<15 \mathrm{~mL} / \mathrm{min} / 1.73 \mathrm{~m}^{2}$ ) or end-stage renal failure on long-term dialysis, terminally ill patients with life expectancy $\leq 3$ months, and those with contraindications for regional citrate anti-coagulation (liver failure or liver cirrhosis, allergy to citrate) were excluded from the study. Informed consent was obtained from patients or their close relatives/surrogates before initiation of CVVH/CVVHD.

Demographic data, comorbidities, and diagnoses were recorded. All patients received conventional therapy for severe sepsis, namely, infective source control, early appropriate antibiotics, fluid challenge and vasopressor infusion, and lung-protected ventilatory strategy based on the Surviving Sepsis Campaign guidelines. ${ }^{[19]}$ A double-lumen 12-F HD catheter (ARROWguard blue plus antimicrobial catheter, Arrow International Inc., USA or GamCath ${ }^{\mathrm{TM}}$ High Flow double-lumen catheter, Baxter-Gambro, Stockholm, Sweden) was inserted into either the internal jugular or femoral vein for vascular access by the attending intensivist/physician. HCO-CVVH or HCO-CVVHD was performed using EMiC2 hemofilter (Fresenius Medical Care, Bad Homburg, Germany) with either anticoagulant citrate dextrose solution or $4 \%$ trisodium citrate as anticoagulant (3-4 mmol of citrate/ citric acid per liter of blood withdrawn). The blood flow was maintained at $100-150 \mathrm{ml} / \mathrm{min}$. Calcium replacement was provided by either calcium gluconate or calcium chloride solution infusion and was titrated to achieve a systemic ionized calcium (iCa) level of $1-1.2 \mathrm{mmol} / \mathrm{L}$ with postfilter iCa level of $0.25-0.3 \mathrm{mmol} / \mathrm{L} .{ }^{[23]}$ The overall fluid withdrawal rate was adjusted to achieve the desired fluid balance at the discretion of physician-in-charge. Each patient received at least one session of $\mathrm{HCO}$ treatment and further treatment sessions were conducted based on the clinician's decision. Disease severity was assessed with the Acute Physiology and Chronic Health Evaluation (APACHE) IV score. ${ }^{[24]}$ Organ dysfunction was quantified using the Sequential
Organ Failure Assessment (SOFA) score. ${ }^{[25]}$ Clinical parameters, vasopressor usage, and laboratory data were recorded. Vasopressor usage was expressed as noradrenaline equivalent, which was calculated as (noradrenaline $[\mu \mathrm{g} / \mathrm{min}]$ ) $+($ dopamine $[\mu \mathrm{g} / \mathrm{kg} / \mathrm{min}] \div 2)+($ adrenaline $[\mu \mathrm{g} / \mathrm{min}])+$ (phenylephrine $[\mu \mathrm{g} / \mathrm{min}] \div 10$ ). ${ }^{[26]}$ Length of stay and survival data were obtained as outcome parameters. Patients' actual mortality was compared with APACHE IV score, and SOFA score predicted mortality. Both of which are widely used and validated ICU mortality prediction models developed from a large sample of ICU patients. ${ }^{[24,25]}$

\section{Statistical analysis}

Sample size calculations were not performed for this case series. Data were reported as frequencies, percentages, median, and interquartile range (IQR). Change of clinical and biochemical parameters over time was assessed with related samples Friedman's two-way analysis of variance by Ranks test. Multivariate analysis was not performed due to small sample size. All analyses were performed using the Statistical Package for the Social Sciences for Windows, version 20 (SPSS Inc., Chicago, IL, USA).

\section{RESULTS}

Between May 2013 and November 2015, seven patients were treated with EMiC2 HCO-CVVH/HCO-CVVHD. Table 1 demonstrates the baseline characteristics of the patients. Patients were aged from 40 to 89 years (median age: 61 years, IQR: 54-83) and were predominantly male (86\%). Around $57 \%$ of them suffered from respiratory tract infection and the others had intra-abdominal sepsis. HCO treatments were initiated quite early with $86 \%$ of patients within KDIGO Stage 1 or 2 . All of them had septic shock and required moderate-to-high dose vasopressor support on initiation of HCO treatment (median noradrenaline equivalent: $16.7 \mu \mathrm{g} / \mathrm{min}$, IQR: 11.1-46.7). All patients had multiorgan failure with median SOFA score of 13 points (IQR: 12-15). They also had high disease severity as illustrated by the high SOFA score-predicted risk of death (median: 0.60, IQR: 0.46-0.82) and APACHE IV-predicted risk of death (median: 0.78, IQR: 0.53-0.82).

Five out of seven $(71 \%)$ recruited patients received only one session of HCO treatment; the median treatment duration for all patients was $71 \mathrm{~h}$ (IQR: 49-72 h), [Table 2]. The majority of them (71\%) had HCO-CVVHD, while others received HCO-CVVH (29\%). Figures 1 and 2 illustrate the changes in noradrenaline equivalent $(P=0.002)$ and the SOFA score $(P=0.001)$ during the first $72 \mathrm{~h}$ after the initiation of $\mathrm{HCO}$ treatment, which indicated clinical improvement.

Figures 3-5 illustrate the changes in cytokine levels (IL-6 with $P<0.001$, IL- 10 with $P=0.001$, and TNF- $\alpha$ with $P=0.021$ ) over time, which indicated good cytokine modulation. Changes in C-reactive protein were less predictable $(P=0.055)$, [Figure 6]. Figure 7 illustrates the changes in the albumin level during the treatment period. 


\begin{tabular}{|c|c|c|c|c|c|c|c|}
\hline Patient & $\begin{array}{l}\text { Gender/ } \\
\text { age }\end{array}$ & Diagnosis & Comorbidities & $\begin{array}{l}\text { APACHE IV } \\
\text { score and } \\
\text { predicted } \\
\text { ROD }\end{array}$ & $\begin{array}{c}\text { SOFA } \\
\text { score and } \\
\text { predicted } \\
\text { risk of death }\end{array}$ & $\begin{array}{l}\text { KDIGO AKI } \\
\text { stage on } \\
\text { initiation of } \\
\text { HCO treatment }\end{array}$ & $\begin{array}{c}\text { Noradrenaline } \\
\text { equivalent on } \\
\text { initiation of } \mathrm{HCO} \\
\text { treatment }(\mu \mathrm{g} / \mathrm{min})\end{array}$ \\
\hline 1 & Male/78 & Cholangitis & DM, CKD & $139 / 0.82$ & $17 / 0.93$ & 2 & 63.3 \\
\hline 2 & Male/54 & Pneumonia and empyema thoracic & $\mathrm{DM}$ & $128 / 0.78$ & $12 / 0.46$ & 1 & 33.3 \\
\hline 3 & Male/40 & Pneumonia & Nil & $127 / 0.82$ & $15 / 0.82$ & 1 & 16.7 \\
\hline 4 & Male/61 & Pneumonia & $\mathrm{AF}$ & $109 / 0.71$ & $13 / 0.60$ & 3 & 5.6 \\
\hline 5 & Male/89 & Fecal peritonitis & $\mathrm{HT}, \mathrm{AF}$ & $115 / 0.53$ & $11 / 0.40$ & 2 & 16.7 \\
\hline 6 & Female/83 & Pneumonia & HT & $176 / 0.96$ & $15 / 0.82$ & 2 & 11.1 \\
\hline 7 & Male/55 & Fecal peritonitis & IHD & $78 / 0.29$ & $13 / 0.60$ & 2 & 46.7 \\
\hline
\end{tabular}

APACHE: Acute Physiology and Chronic Health Evaluation; KDIGO: Kidney Disease Improving Global Outcomes; SOFA: Sequential Organ Failure Assessment; HCO: High cutoff; DM: Diabetes mellitus; CKD: Chronic kidney disease; AF: Atrial fibrillation; HT: Hypertension; IHD: Ischemic heart disease; AKI: Acute kidney injury; ROD: Risk of death

\begin{tabular}{llccccccc}
\hline \multicolumn{2}{l}{ Table 2: Treatment and outcome parameters (high-cutoff hemofiltration/hemodialysis) } \\
\hline Patient & $\begin{array}{l}\text { Treatment } \\
\text { type }\end{array}$ & $\begin{array}{c}\text { Number of } \\
\text { HCO filter used }\end{array}$ & $\begin{array}{c}\text { Total treatment duration } \\
\text { using HCO filter (h) }\end{array}$ & $\begin{array}{c}\text { Vasopressor } \\
\text { duration (h) }\end{array}$ & $\begin{array}{c}\text { ICU } \\
\text { survival }\end{array}$ & $\begin{array}{c}\text { Hospital } \\
\text { survival }\end{array}$ & $\begin{array}{c}\text { 28-day } \\
\text { survival }\end{array}$ & $\begin{array}{c}\text { ICU and hospital } \\
\text { LOS (days) }\end{array}$ \\
\hline 1 & CVVH & 2 & 60 & 113 & Yes & Yes & Yes & $7 / 35$ \\
2 & CVVH & 1 & 72 & 196 & Yes & Yes & Yes & $12 / 105$ \\
3 & CVVHD & 1 & 22 & 511 & No & No & No & $21 / 21$ \\
4 & CVVHD & 1 & 71 & 132 & Yes & No & Yes & $27 / 163$ \\
5 & CVVHD & 1 & 49 & 52 & Yes & Yes & Yes & $6 / 54$ \\
6 & CVVHD & 3 & 127 & 51 & Yes & Yes & Yes & $8 / 20$ \\
7 & CVVHD & 1 & 72 & 25 & Yes & Yes & Yes & $6 / 16$ \\
\hline
\end{tabular}

CVVH/CVVHD: Continuous venovenous hemofiltration/hemodialysis; HCO: High cutoff; LOS: Length of stay; ICU: Intensive Care Unit

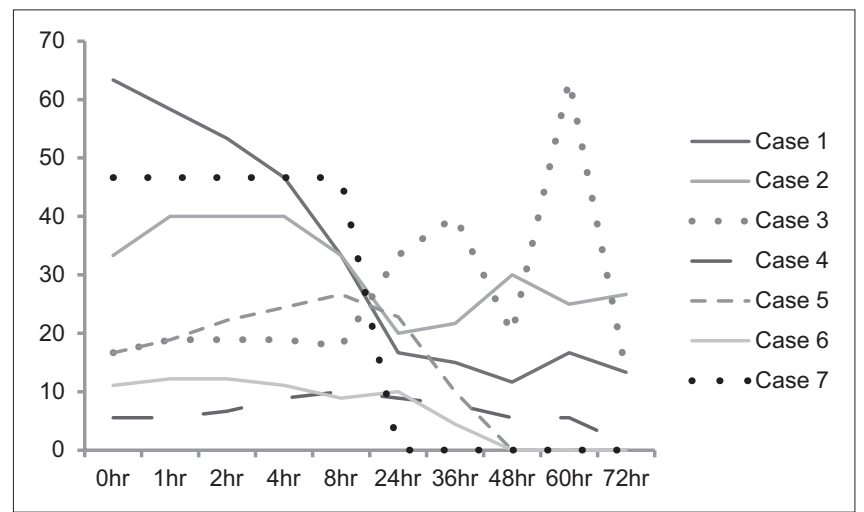

Figure 1: Noradrenaline equivalent $(\mu \mathrm{g} / \mathrm{min})$ changes during high-cutoff treatment. $P=0.002$ for noradrenaline changes over time, cases 3 and 4 were hospital nonsurvivors

The median albumin level on initiation of HCO treatment was $21 \mathrm{~g} / \mathrm{L}$ (IQR: 20-27) and the trough level occurred at $2 \mathrm{~h}$ after the initiation of HCO treatment (median: $20 \mathrm{~g} / \mathrm{L}$, IQR: $19-25, P=0.029)$. Albumin supplementation was not provided to any of the recruited patients. Patient 3 developed significant hemodynamic collapse after $22 \mathrm{~h}$ of HCO treatment, which required early termination of treatment. Citrate toxicity was excluded and the treating physician attributed this event to clinical deterioration of the underlying pneumonia. The patient was subsequently started

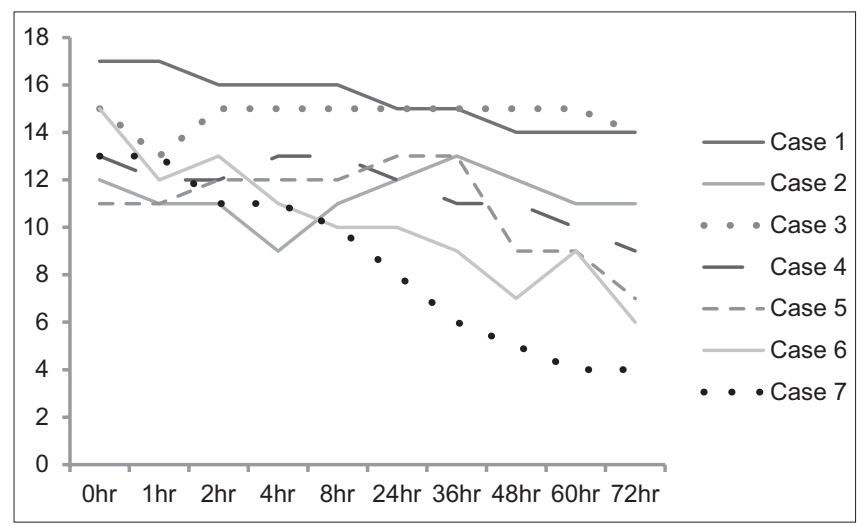

Figure 2: Sequential Organ Failure Assessment score changes during high-cutoff treatment. $P=0.001$ for Sequential Organ Failure Assessment score changes over time, cases 3 and 4 were hospital nonsurvivors

on conventional citrate-based CVVH after stabilization but deteriorated again in subsequent days, which resulted in ICU mortality. For the other patients, HCO treatment was well tolerated as evidenced by the stable hemodynamic and progressive decrement of noradrenaline use during the treatment. All but one patient were discharged from the ICU. The actual hospital mortality rate was $29 \%$, which was lower than that predicted by SOFA (actual-to-predicted risk of death $=0.43$ ) and APACHE IV score (actual over predicted risk of death $=0.41$ ). 


\section{Discussion}

This case series summarizes our clinical experience on the use of an $\mathrm{EMiC} 2 \mathrm{HCO}$ hemofilter for the treatment of septic shock patients with AKI. Our findings show that patients who received HCO treatment could achieve good cytokine modulation. Clinical improvement was observed after $24-36 \mathrm{~h}$ of treatment as indicated by the reduction of vasopressor usage and SOFA score. Overall, the patient outcomes were satisfactory, as illustrated by the low standardized mortality ratio (actual-to-predicted risk of death) based on commonly used mortality prediction models. Compared with the APACHE IV standardized mortality ratio in our previous cases with septic shock that required renal replacement therapy (RRT) $(0.74$ among 186 patients who received standard therapy vs. 0.41 among 7 patients treated with EMiC2 HCO therapy, $P=0.0547$ ), the outcome of patients who received EMiC2 HCO treatment appeared acceptable.

The specifications of some commonly used HCO filters are shown in Table 3. The cutoff level of the EMiC2 HCO hemofilter $(40 \mathrm{kDa})$ used in our patients was lower than that of the PSH1, P2SH, or HCO1100 hemofilter (45-60 KDa) studied previously. ${ }^{[15,16,32,33]}$ Therefore, we expect lower cytokine clearance and also less albumin loss. Moreover,

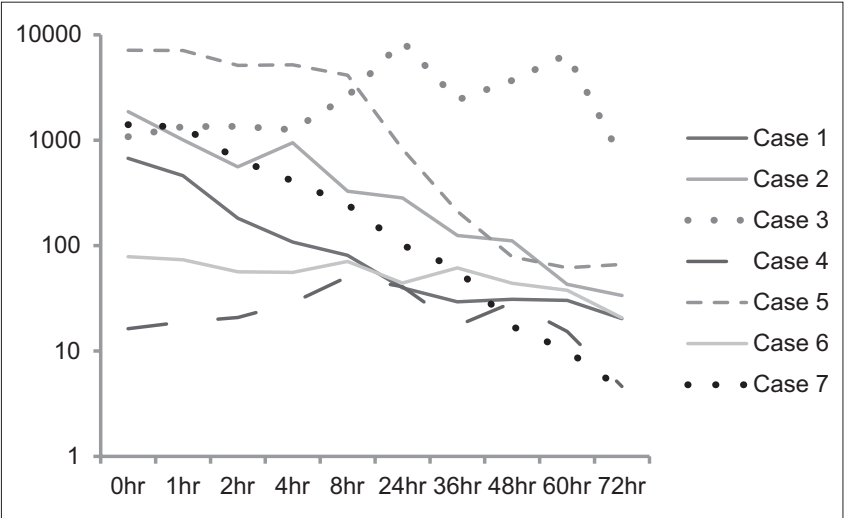

Figure 3: Interleukin-6 (pg/mL) changes during high-cutoff treatment. $P<0.001$ for interleukin- 6 changes over time, cases 3 and 4 were hospital nonsurvivors the membrane structure of the polysulfone-based EMiC2 hemofilter differs from the other polyarylethersulfone-based HCO hemofilters (e.g., PSH1, P2SH, or HCO1100 hemofilters) in terms of protein retention capacity, which may again affect albumin loss. ${ }^{[35]}$ Published clinical data on the use of EMiC2 hemofilter for septic patients are limited. Yaroustovsky et al. reported the use of selective LPS adsorption procedures (Toraymyxin PMX-F cartridges; Toray, Japan) in combination with hemodialysis using EMiC2 $\mathrm{HCO}$ hemofilter for cardiac surgical patients with severe sepsis. ${ }^{[27]}$ Compared with those patients on standard treatments, patients on combination therapies showed significant hemodynamic and oxygenation improvement. Potential mortality benefit was also observed. However, the net benefit of EMiC2 hemofilter is not clear. Therefore, our data did provide further clinical information for this novel $\mathrm{HCO}$ hemofilter.

Morgera et al. published the first study on the use of $\mathrm{HCO}$ hemofiltration (PSH1, cutoff: $60 \mathrm{KDa}$, surface area: $0.6 \mathrm{~m}^{2}$, Gambro Corporate Research, Hechingen, Germany) among septic shock patients and showed good IL-6 (but not TNF- $\alpha$ ) clearance with fair hemodynamic tolerance. ${ }^{[15]}$ Restoration of peripheral blood mononuclear cell proliferation was also observed in septic patients treated with HCO hemofiltration using P2SH filter (P2SH, cutoff: $60 \mathrm{KDa}$, surface area:

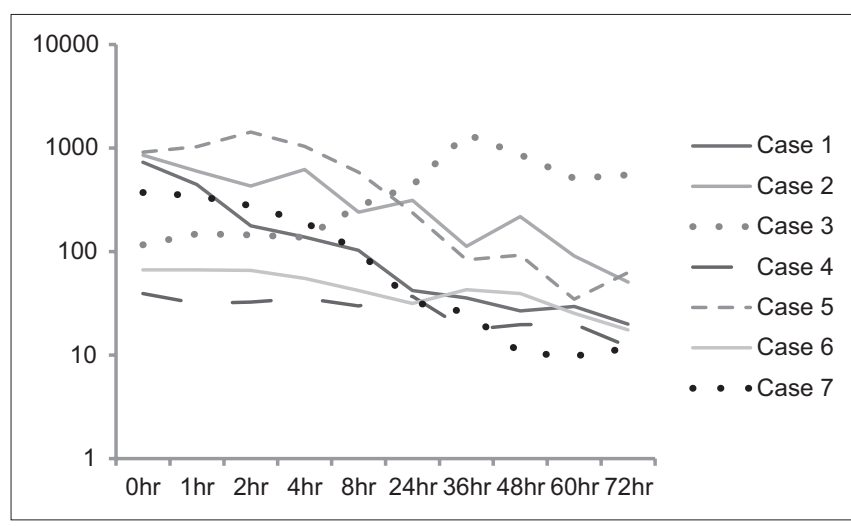

Figure 4: Interleukin-10 (pg/mL) changes during high-cutoff treatment. $P=0.001$ for interleukin- 10 changes over time, cases 3 and 4 were hospital nonsurvivors

Table 3: Comparison between different types of high-cutoff filters

\begin{tabular}{|c|c|c|c|c|c|}
\hline Manufacturer & FMC & Baxter-Gambro & Gambro & Gambro & Gambro \\
\hline Filter name & EMiC2 & Septex & HCO 1100 & $\mathrm{P} 2 \mathrm{SH}$ & PSH1 \\
\hline Material & Polysulfone & PAES/PES & PAES/PES & PAES/PES & PAES/PES \\
\hline Treatment modality & CVVHD/CVVH/SLED & $\mathrm{CVVHD} / \mathrm{CVVH}$ & HD & $\mathrm{CVVH} / \mathrm{CVVHD}$ & $\mathrm{HF}$ \\
\hline Effective surface area $\left(\mathrm{m}^{2}\right)$ & 1.8 & 1.1 & 1.1 & 1.1 & 0.6 \\
\hline Cut off & $40 \mathrm{kDa}$ & $60 \mathrm{kDa}$ & $45-60 \mathrm{kDa}$ & $60 \mathrm{kDa}$ & $60 \mathrm{kDa}$ \\
\hline Target molecules & Cytokines, light chain, myoglobin & Cytokines & Cytokines & Cytokines & Cytokines \\
\hline Sieving coefficient for albumin & 0.01 & 0.1 & $\mathrm{~N} / \mathrm{A}$ & $\mathrm{N} / \mathrm{A}$ & $\mathrm{N} / \mathrm{A}$ \\
\hline Usual treatment duration $(\mathrm{h})$ & 72 & $24-72$ & $4-6$ & $24-72$ & 12 \\
\hline Human in vivo studies involved [reference] & {$[27-29]$} & {$[30,31]$} & {$[17,32]$} & {$[33,34]$} & {$[15]$} \\
\hline
\end{tabular}

N/A: Not available; HD: Hemodialysis; FMC: Fresenius medical care; CVVH/CVVHD: Continuous venovenous hemofiltration/hemodialysis; SLED: Sustained low-efficiency dialysis; HCO: High cutoff; PAES/PES: Polyarylethersulfone/Polyethersulfone; HF: Hemofiltration 


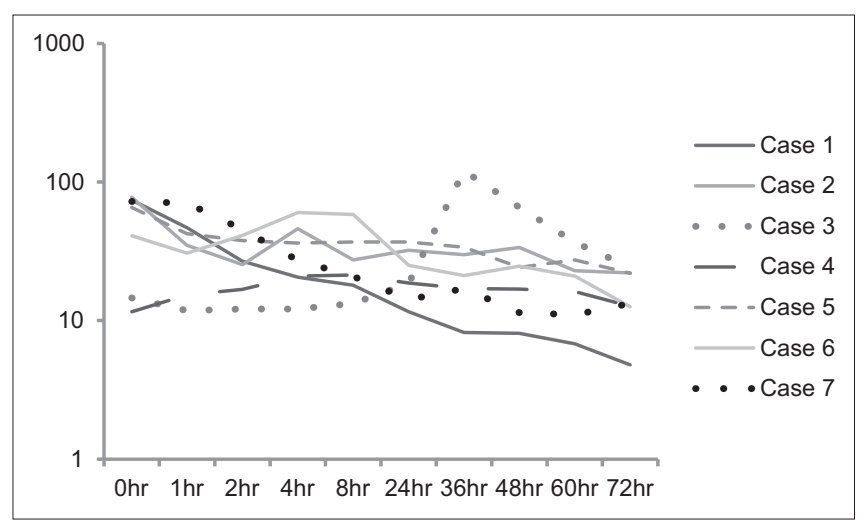

Figure 5: Tumor necrosis factor-alpha $(\mathrm{pg} / \mathrm{mL})$ changes during high-cutoff treatment. $P=0.021$ for tumor necrosis factor-alpha changes over time, cases 3 and 4 were hospital nonsurvivors

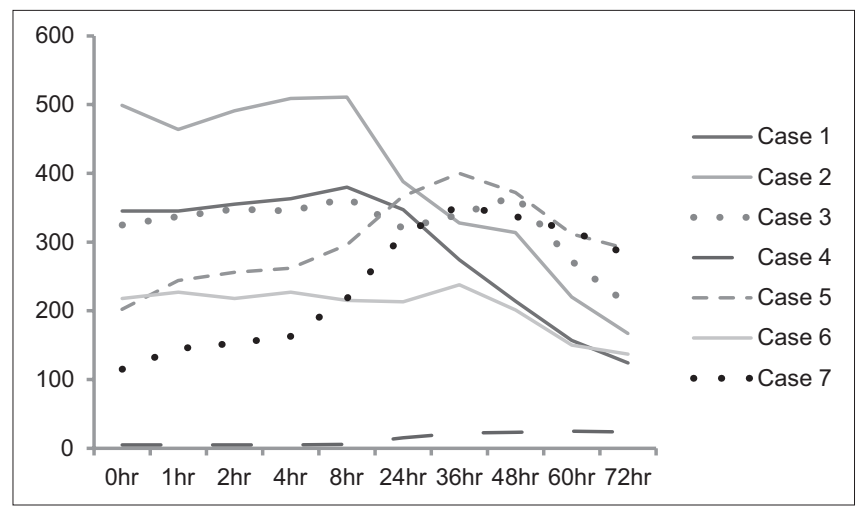

Figure 6: C-reactive protein ( $\mathrm{mg} / \mathrm{L})$ changes during high-cutoff treatment. $P=0.055$ for $C$-reactive protein changes over time, cases 3 and 4 were hospital nonsurvivors

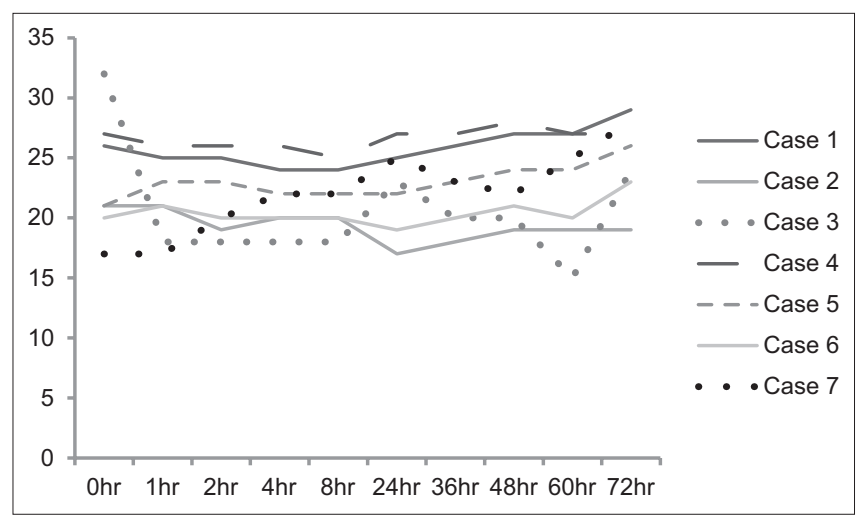

Figure 7: Albumin $(\mathrm{g} / \mathrm{L})$ changes during high-cutoff treatment. $P=0.029$ for albumin changes over time, cases 3 and 4 were hospital nonsurvivors

$1.1 \mathrm{~m}^{2}$, Gambro Corporate Research, Hechingen, Germany), probably by eliminating the circulating immunomodulatory mediators. ${ }^{[33]}$ Subsequently, Morgera et al. conducted an randomized controlled trial (RCT) that involved thirty septic AKI patients who were randomized to $\mathrm{HCO}(\mathrm{P} 2 \mathrm{SH})$ or conventional (PF11S, cutoff: $30 \mathrm{KDa}$, surface area: $1.1 \mathrm{~m}^{2}$, Gambro, Hechingen, Germany) hemofiltration. The HCO group showed a significant decline in vasopressor use and cytokine (IL-6 and IL-1Ra) levels. ${ }^{[16]}$ Compared with the treatment group in Morgera et al.'s study, ${ }^{[16]}$ our patients had poorer clinical status as illustrated by higher APACHE II score (median: 25 points; IQR: 22-32 for Morgera's treatment group, vs. median: 29 points; IQR: $25-38$ for our patients) despite having similar noradrenaline usage (median: $0.30 \mu \mathrm{g} / \mathrm{kg} / \mathrm{min}$; IQR: $0.10-0.48$ vs. median: $0.28 \mu \mathrm{g} / \mathrm{kg} / \mathrm{min}$; IQR: $0.23-0.82$ ). The baseline IL-6 level was higher for our patients compared with the treatment group in Morgera's study (median: 1078 pg/ml; IQR: 78-1861, vs. median: 243 pg/ml; IQR: $58-574)$. We also demonstrated similar reduction in vasopressor usage during $\mathrm{HCO}$ treatment. The 28-day mortality for our patients was $14 \%$ versus $61 \%$ for the treatment group in Morgera's study. However, without a control group in our study, the net benefit of this new hemofilter could not be delineated. In fact, rapid improvement of the clinical and biochemical parameters could also be due to conventional sepsis treatments based on the recommendation from the Surviving Sepsis Campaign guideline (e.g., infective source control with surgery or interventional radiological procedures, early antibiotic administration, adequate fluid challenge, and appropriate vasopressor/inotropic therapy). ${ }^{[19]}$ The largest RCT on the use of HCO hemofilter for treatment of sepsis was the High Cut-Off Continuous Veno-venous Haemodialysis in Patients Treated for Acute Renal Failure After Systemic Inflammatory Response Syndrome/Septic Shock (HICOSS) study, which was published in abstract form. ${ }^{[32]}$ The estimated sample size was 120 patients and the patients were randomized to receive either HCO-CVVHD (HCO 1100, cutoff: 45-60 KDa, surface area: $1.1 \mathrm{~m}^{2}$, Gambro Corporate Research, Hechingen, Germany) or CVVHD using conventional high-flux hemofilter. The study was terminated early because of a lack of difference between groups after 81 patients had been recruited. There was no difference in 28-day mortality, vasopressor use, duration of mechanical ventilation, ICU length of stay, or albumin level between groups. ${ }^{[32]}$ This underpowered RCT (due to premature termination) cannot provide a clear answer on the potential benefit of $\mathrm{HCO}$ hemofiltration/HD in septic patients, and a further large-scale prospective RCT is recommended.

Compared with cytokine hemoadsorption, high-volume hemofiltration, or coupled plasma filtration adsorption, the equipment used for $\mathrm{HCO}$ hemofiltration/HD is easily available in a general ICU. The associated technique (i.e., CVVH or CVVHD) is also well established and requires minimal extra training for successful implementation. The pore sizes of HCO membranes are 2-3 fold larger than conventional high-flux membranes (which have a pore size of $0.003-0.006 \mu \mathrm{m}$ ) and one-twentieth that of plasma filter membranes (which have a pore size of around $0.2 \mu \mathrm{m}) .^{[14]}$ The nominal cutoff points for HCO membranes range from 60 to $150 \mathrm{kDa}$ and the clinical cutoff points in the blood range from 40 to $100 \mathrm{kDa} \cdot{ }^{[14]} \mathrm{By}$ increasing the pore size of the hemofilter membrane, the sieving coefficients (SCs) of various inflammatory mediators increase significantly at the expense of the loss of albumin (66 kDa), antithrombin-III $(60 \mathrm{kDa})$, protein $\mathrm{C}(62 \mathrm{kDa})$, and many other 
vital proteins. ${ }^{[36]}$ Reducing the pore size slightly can limit vital protein loss, but this also decreases cytokine removal. These membranes are usually made from polyarylethersulfone/ polyethersulfone, polysulfone, or cellulose triacetate ${ }^{[14]}$ Initial ex vivo studies showed that the SCs for TNF- $\alpha(17 \mathrm{kDa}$, 27\%-78\%), IL-6 (26 kDa, 54\%-99\%), and IL-1 $\beta$ (17 kDa, 58-81\%) are very good. ${ }^{[15,37-40]}$ A systematic review by Atan et al. on ex vivo studies showed that HCO hemofiltration displayed the greatest consistency in cytokine removal when compared with standard hemofiltration. ${ }^{[4]}$ Albumin loss was comparable between $\mathrm{HCO}$ hemofiltration, HCO HD, and $\mathrm{HCO}$ hemodiafiltration, ${ }^{[41]}$ but cytokine clearance may be better with a convective technique ${ }^{[34]}$ For our patients, the median albumin level decreased by $<5 \%$ ( 21 to $20 \mathrm{~g} / \mathrm{L}$ ) during the HCO treatment period and therefore albumin replacement might not be necessary. This albumin drop may be related to HCO treatment, but hemodilution or redistribution into the extravascular space can be the cause as well. With continued HCO treatment, hemofilter clogging occurs due to the deposition of protein and red cells on the membrane surface. ${ }^{[18]}$ This decreases the SC of larger molecules and also limits albumin loss. ${ }^{[18,42]}$

\section{Limitations}

First, this case series is limited by the small sample size. However, the clinical experience of this novel EMIC2 HCO hemofilter is limited. Our data could provide a useful add-on for this field of study. Second, the cytokine assay was not readily available before randomization and therefore we could not target patients with hypercytokinemia who might be more responsive to the cytokine reductive therapy. Third, changes in cytokine levels might be contributed by decreased production from inflammatory cells in response to the appropriate treatment for sepsis per se. Cytokine assay within effluents should be useful to quantify RRT-associated removal, but this technique is not available locally. The clinical improvement observed could also be due to the effect of conventional treatments including antibiotics, other supportive measures, and infection source control. Without a control group in our study, the net benefit of this new hemofilter could not be ascertained. Finally, this was a single-center study in which local practice on the management of septic patients might alter the final clinical outcome. We followed the Surviving Sepsis Campaign guidelines closely to minimize this confounding factor. ${ }^{[19]}$

\section{Conclusion}

This case series shows that HCO-CVVH/CVVHD using EMiC2 hemofilter may provide good cytokine modulation, when used along with good quality standard sepsis therapy. A further large-scale prospective RCT is recommended to delineate the potential beneficial effect of this novel treatment in septic shock patients with or without renal impairment.

\section{Acknowledgment}

We would like to acknowledge the renal nurses in our ICU for their support in performing the HCO treatments.

\section{Financial support and sponsorship}

Nil.

\section{Conflicts of interest}

There are no conflicts of interest.

\section{References}

1. Prince LR, Whyte MK, Sabroe I, Parker LC. The role of TLRs in neutrophil activation. Curr Opin Pharmacol 2011;11:397-403.

2. Nakayama H, Kurokawa K, Lee BL. Lipoproteins in bacteria: Structures and biosynthetic pathways. FEBS J 2012;279:4247-68.

3. Zarbock A, Gomez H, Kellum JA. Sepsis-induced acute kidney injury revisited: Pathophysiology, prevention and future therapies. Curr Opin Crit Care 2014;20:588-95.

4. Angus DC, van der Poll T. Severe sepsis and septic shock. N Engl J Med 2013;369:840-51.

5. Gomez H, Ince C, De Backer D, Pickkers P, Payen D, Hotchkiss J, et al. A unified theory of sepsis-induced acute kidney injury: Inflammation, microcirculatory dysfunction, bioenergetics, and the tubular cell adaptation to injury. Shock 2014;41:3-11.

6. Wang C, Sun J, Zheng J, Guo L, Ma H, Zhang Y, et al. Low-dose hydrocortisone therapy attenuates septic shock in adult patients but does not reduce 28-day mortality: A meta-analysis of randomized controlled trials. Anesth Analg 2014;118:346-57.

7. Kalil AC, Sun J. Low-dose steroids for septic shock and severe sepsis: The use of Bayesian statistics to resolve clinical trial controversies. Intensive Care Med 2011;37:420-9.

8. Alejandria MM, Lansang MA, Dans LF, Mantaring JB $3^{\text {rd }}$. Intravenous immunoglobulin for treating sepsis, severe sepsis and septic shock. Cochrane Database Syst Rev 2013;16:CD001090.

9. Bernard GR, Francois B, Mira JP, Vincent JL, Dellinger RP, Russell JA, et al. Evaluating the efficacy and safety of two doses of the polyclonal anti-tumor necrosis factor- $\alpha$ fragment antibody AZD9773 in adult patients with severe sepsis and/or septic shock: Randomized, double-blind, placebo-controlled phase IIb study. Crit Care Med 2014;42:504-11.

10. Ronco C, Tetta C, Mariano F, Wratten ML, Bonello M, Bordoni V, et al. Interpreting the mechanisms of continuous renal replacement therapy in sepsis: The peak concentration hypothesis. Artif Organs 2003;27:792-801.

11. Rimmelé T, Kellum JA. Clinical review: Blood purification for sepsis. Crit Care 2011;15:205.

12. Cole L, Bellomo R, Hart G, Journois D, Davenport P, Tipping P, et al. A phase II randomized, controlled trial of continuous hemofiltration in sepsis. Crit Care Med 2002;30:100-6.

13. Payen D, Mateo J, Cavaillon JM, Fraisse F, Floriot C, Vicaut E, et al. Impact of continuous venovenous hemofiltration on organ failure during the early phase of severe sepsis: A randomized controlled trial. Crit Care Med 2009;37:803-10.

14. Haase M, Bellomo R, Morgera S, Baldwin I, Boyce N. High cut-off point membranes in septic acute renal failure: A systematic review. Int $\mathrm{J}$ Artif Organs 2007;30:1031-41.

15. Morgera S, Rocktäschel J, Haase M, Lehmann C, von Heymann C, Ziemer S, et al. Intermittent high permeability hemofiltration in septic patients with acute renal failure. Intensive Care Med 2003;29:1989-95.

16. Morgera S, Haase M, Kuss T, Vargas-Hein O, Zuckermann-Becker H, Melzer $\mathrm{C}$, et al. Pilot study on the effects of high cutoff hemofiltration on the need for norepinephrine in septic patients with acute renal failure. Crit Care Med 2006;34:2099-104.

17. Haase M, Bellomo R, Baldwin I, Haase-Fielitz A, Fealy N, Davenport P, et al. Hemodialysis membrane with a high-molecular-weight cutoff and cytokine levels in sepsis complicated by acute renal failure: A phase 1 randomized trial. Am J Kidney Dis 2007;50:296-304.

18. Villa G, Zaragoza JJ, Sharma A, Neri M, De Gaudio AR, Ronco C, et al. Cytokine removal with high cut-off membrane: Review of literature. Blood Purif 2014;38:167-73.

19. Rhodes A, Evans LE, Alhazzani W, Levy MM, Antonelli M, Ferrer R, et al. Surviving sepsis campaign: International guidelines 
for management of sepsis and septic shock: 2016. Crit Care Med 2017;45:486-552.

20. Dellinger RP, Levy MM, Carlet JM, Bion J, Parker MM, Jaeschke R, et al. Surviving sepsis campaign: International guidelines for management of severe sepsis and septic shock: 2008. Crit Care Med 2008;36:296-327.

21. Dellinger RP, Levy MM, Rhodes A, Annane D, Gerlach H, Opal SM, et al. Surviving sepsis campaign: International guidelines for management of severe sepsis and septic shock: 2012. Crit Care Med 2013:41:580-637.

22. Khwaja A. KDIGO clinical practice guidelines for acute kidney injury. Nephron Clin Pract 2012;120:c179-84.

23. Shum HP, Yan WW, Chan TM. Risks and benefits of citrate anticoagulation for continuous renal replacement therapy. Hong Kong Med J 2015;21:149-54.

24. Zimmerman JE, Kramer AA, McNair DS, Malila FM. Acute physiology and chronic health evaluation (APACHE) IV: Hospital mortality assessment for today's critically ill patients. Crit Care Med 2006;34:1297-310.

25. Vincent JL, Moreno R, Takala J, Willatts S, De Mendonça A, Bruining $\mathrm{H}$, et al. The SOFA (Sepsis-related organ failure assessment) score to describe organ dysfunction/failure. On behalf of the working group on sepsis-related problems of the European Society of Intensive Care Medicine. Intensive Care Med 1996;22:707-10.

26. Patel BM, Chittock DR, Russell JA, Walley KR. Beneficial effects of short-term vasopressin infusion during severe septic shock. Anesthesiology 2002;96:576-82.

27. Yaroustovsky M, Abramyan M, Krotenko N, Popov D, Plyushch M, Rogalskaya E, et al. Combined extracorporeal therapy for severe sepsis in patients after cardiac surgery. Blood Purif 2014;37:39-46.

28. Schmidt JJ, Hafer C, Clajus C, Hadem J, Beutel G, Schmidt BM, et al. New high-cutoff dialyzer allows improved middle molecule clearance without an increase in albumin loss: A clinical crossover comparison in extended dialysis. Blood Purif 2012;34:246-52.

29. Schmidt JJ, Hafer C, Spielmann J, Hadem J, Schönenberger E, Schmidt BM, et al. Removal characteristics and total dialysate content of glutamine and other amino acids in critically ill patients with acute kidney injury undergoing extended dialysis. Nephron Clin Pract 2014;126:62-6.

30. Chelazzi C, Villa G, D'Alfonso MG, Mancinelli P, Consales G, Berardi $\mathrm{M}$, et al. Hemodialysis with high cut-off hemodialyzers in patients with multi-drug resistant gram-negative sepsis and acute kidney injury: A Retrospective, case-control study. Blood Purif 2016;42:186-93.

31. Villa G, D’Alfonso MG, Di Maggio P, Berardi M, Chelazzi C, Caldini AL, et al. Role of hemodialysis with high cut-off membranes in a patient with a non-recognized leishmaniasis. Blood Purif 2014;38:239-41.

32. Honore P, Beck W. High Cut-OffContinuous Veno-Venous Hemodialysis (CVVHD) in Patients Treated for Acute Renal Failure After Systemic Inflammatory Response Syndrome (SIRS)/Septic Shock (HICOSS). $10^{\text {th }}$ ed. Florence, Italy: WFSCICCM; 2009.

33. Morgera S, Haase M, Rocktäschel J, Böhler T, von Heymann C, Vargas-Hein $\mathrm{O}$, et al. High permeability haemofiltration improves peripheral blood mononuclear cell proliferation in septic patients with acute renal failure. Nephrol Dial Transplant 2003;18:2570-6.

34. Morgera S, Slowinski T, Melzer C, Sobottke V, Vargas-Hein O, Volk T, et al. Renal replacement therapy with high-cutoff hemofilters: Impact of convection and diffusion on cytokine clearances and protein status. Am J Kidney Dis 2004;43:444-53.

35. Namekawa K, Fukuda M, Matsuda M, Yagi Y, Yamamoto K, Sakai K, et al. Nanotechnological characterization of human serum albumin adsorption on wet synthetic polymer dialysis membrane surfaces. ASAIO J 2009;55:236-42.

36. Naka T, Haase M, Bellomo R. 'Super high-flux' or 'high cut-off' hemofiltration and hemodialysis. Contrib Nephrol 2010;166:181-9.

37. Morgera S, Klonower D, Rocktäschel J, Haase M, Priem F, Ziemer S, et al. TNF-alpha elimination with high cut-off haemofilters: A feasible clinical modality for septic patients? Nephrol Dial Transplant 2003;18:1361-9.

38. Uchino S, Bellomo R, Goldsmith D, Davenport P, Cole L, Baldwin I, et al. Super high flux hemofiltration: A new technique for cytokine removal. Intensive Care Med 2002;28:651-5.

39. Uchino S, Bellomo R, Goldsmith D, Davenport P, Cole L, Baldwin I, et al. Cytokine removal with a large pore cellulose triacetate filter: An ex vivo study. Int J Artif Organs 2002;25:27-32.

40. Bordoni V, Bolgan I, Brendolan A, Crepaldi C, Gastaldon F, D'intini V, et al. Caspase-3 and -8 activation and cytokine removal with a novel cellulose triacetate super-permeable membrane in an in vitro sepsis model. Int J Artif Organs 2003;26:897-905.

41. Atan R, Crosbie D, Bellomo R. Techniques of extracorporeal cytokine removal: A systematic review of the literature. Blood Purif 2012;33:88-100

42. Joannidis M, Oudemans-van Straaten HM. Clinical review: Patency of the circuit in continuous renal replacement therapy. Crit Care 2007;11:218. 